\title{
Effect of Occupational Activity on Ambulatory Blood Pressure Behaviour
}

\author{
J Pereira, A Teixeira, T Pereira
}

European Journal of Public Health, Volume 29, Issue Supplement_1, April 2019, ckz034.075, https://doi.org/10.1093/eurpub/ckz034.075

Published: 27 April 2019

\section{Cite Permissions Share $\mathbf{v}$}

Topic: blood pressure

Issue Section: Oral Communication

Introduction: Hypertension (HBP) is a key risk factor for cardiovascular diseases, being strongly associated with behavioural and environmental aspects of living. Professional activities, amongst thers that take place throughout the day, are responsible for important blood pressure (BP) variations and may increase it.

Objectives: This study aims at ascertaining the blood pressure profile and variation in teachers, during a typical teaching session.

Methods: Ambulatory Blood Pressure Monitoring (ABPM) was performed in a cohort of 21 university teachers during a typical professional day, comprising the following periods: $24^{-}$ hour period, day period, night period, morning period, 2 hours before class, during class, 2 hours after class, aerobic exercise period and $1 .$.

(c) The Author(s) 2019. Published by Oxford University Press on behalf of the European Public Health Association. All rights reserved. 
This article is published and distributed under the terms of the Oxford University Press, Standard Journals

Publication Model

(https://academic.oup.com/journals/pages/open_access/funder_policies/chorus/standard_publication_model)

You do not currently have access to this article.

\section{Comments}

0 Comments

Add comment

\section{Sign in}

Don't already have an Oxford Academic account? Register

\section{Oxford Academic account}

Email address / Username

\section{Password}

\section{European Public Health Association members}

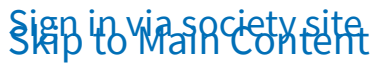

\section{Sign in via your Institution}


Sign in

\section{Purchase}

Subscription prices and ordering

\section{Short-term Access}

To purchase short term access, please sign in to your Oxford Academic account above.

Don't already have an Oxford Academic account? Register

Effect of Occupational Activity on Ambulatory Blood Pressure Behaviour - 24 Hours access

EUR $€ 36.00 \quad$ GBP $£ 28.00 \quad$ USD $\$ 45.00$

\section{Rental}

This article is also available for rental through DeepDyve.

\section{Email alerts}

New issue alert

Advance article alerts

Article activity alert

Skip tôgeivin exclusive offers and updates

from Oxford Academic 


\section{Related articles in}

Google Scholar

\section{Related articles in PubMed}

High prevalence of systemic hypertension in pediatric patients with moyamoya disease years after surgical treatment.

Pressure Injuries Treated With Anodal and Cathodal High-voltage Electrical Stimulation: the Effect on Blood Serum Concentration of Cytokines and Growth Factors in Patients With Neurological Injuries. A Randomized Clinical Study.

Disentangling the Gordian knot of local metabolic control of coronary blood flow.

Clinical safety of blood flow restricted training? A comprehensive review of altered muscle metaboreflex in cardiovascular disease during ischemic exercise.

\section{Citing articles via}

Google Scholar

Crossref

\section{\begin{tabular}{l|l|l} 
Latest & Most Read & Most Cited
\end{tabular}}

Benefits and challenges of Big Data in healthcare: an overview of the European initiatives

Towards an equitable digital public health era: promoting equity through a health literacy perspective

How to govern the digital transformation of health services

Skip to Main Content

Public health digitalization in Europe: EUPHA

vision, action and role in digital public health 
The second information revolution:

digitalization brings opportunities and concerns

for public health

About The European Journal of Public Health

Editorial Board

Author Guidelines

Contact EUPHA

Facebook

\section{Online ISSN 1464-360X}

Print ISSN 1101-1262

Copyright (c) 2019 European Public Health Association

About Us

Contact Us

Careers

Help

Access \& Purchase

Rights \& Permissions

Open Access

\section{Resources}

Authors

Librarians

Societies

Sponsors \& Advertisers

Press \& Media

Agents

\section{Twitter}

Purchase

Recommend to your Library

Advertising and Corporate Services

Journals Career Network

\section{Connect}

Join Our Mailing List

OUPblog

Twitter

Facebook

YouTube

Tumblr

\section{Explore}

Shop OUP Academic

Oxford Dictionaries

Oxford Index

Epigeum

OUP Worldwide

University of Oxford 
Oxford University Press is a department of the University of

oxford. It furthers the University's objective of excellence in research, scholarship, and education by publishing worldwide

\section{OXFORD}

UNIVERSITY PRESS

Copyright @ 2019 Oxford University Press Cookie Policy Privacy Policy Legal Notice Site Map Accessibility Get Adobe Reader 